\title{
Studies of Coastal Ocean \\ Dynamics and Processes Using
Emerging Optical Technologies
}

BY TOMMY D. DICKEY

Increasing emphasis is being placed upon scientific research, monitoring, and management of the coastal ocean for many compelling reasons. It is estimated that over 60 percent of the human population dwells within the coastal zone (defined as the region lying within $-200 \mathrm{~m}$ and $+200 \mathrm{~m}$ of mean sea level; Pernetta and Milliman, 1995). Benefits derived from coastal waters include fisheries, natural resources, transport of goods, and recreation. These same waters are often adversely affected by pollution from river and storm runoff, spills and resuspension of waste materials, input of fertilizers causing eutrophication and sometimes anoxia, blooms of harmful algal species (e.g., red tides, brown tides, fish kills), and transport of ecologically damaging non-endemic species. The role of the coastal ocean in global carbon cycling and sequestration remains uncertain; however, optical tools have already proven valuable for biogeochemical as well as pollution and ecological studies (e.g., Dickey, 2001, 2003). Other important applications of coastal optical measurements in-

Tommy D. Dickey (Tommy.Dickey@opl.ucsb. edu) is Professor, Ocean Physics Laboratory, University of California, Santa Barbara, Goleta, CA. clude prediction of underwater visibility and water depth for purposes including navigation, shipping, and tactical naval operations.

Bio-optical oceanography, also termed bio-optics, concerns the interactions between organisms and light in the sea, and encompasses studies of oceanic organisms, anthropogenic effects. Further, the influences of the ocean bottom (which varies greatly from rocky to sandy to muddy and from barely vegetated to densely vegetated), on water column light fields and water-leaving radiance (i.e., optically shallow waters) have only begun to be explored. Nonetheless,

\section{...within the past decade, bio-optical and optical oceanography have matured to the point that most plans for coastal experiments,} observations, and observatories, regardless of application, include in situ and remote-sensing optical instrumentation and bio-optical models as essential components.

these organisms' effects on the propagation and spectral distribution of light (color) in the sea, and in turn the effects of light intensity and spectral quality on these organisms. Bio-optical oceanography, as the name implies, is an interdisciplinary science with biology and the optical branch of physics defining the principal intersection point. Much bio-optical research, particularly in the area of remote sensing, has focused on the open ocean, rather than the far more complex and biologically productive coastal ocean, which again is highly influenced by terrestrial and within the past decade, bio-optical and optical oceanography have matured to the point that most plans for coastal experiments, observations, and observatories, regardless of application, include in situ and remote-sensing optical instrumentation and bio-optical models as essential components. Much of the recent progress in bio-optics can be attributed to rapidly advancing optical instrumentation and modeling, which has been well described in review articles and reports (e.g., Sathyendranath, 2000; Ackleson, 2001; Dickey, 2001, 2003; Dickey and Chang, 2001; 
Chang et al., 2003; see Oceanography, volume 14[3], 2001, Special Issue: Focus on Ocean Optics; and the information available at: http://www.ioccg.org). Furthermore, the increasing interest in bio-optics results in large part from its wide-ranging and pertinent subject matter, and its application to the physics, biology, and chemistry of the ocean.

\section{HyCODE investigators are developing fully three- dimensional models that incorporate physical-biological- optical components and interactions.}

Coastal experiments in which bio-optical oceanography has a played central role within the past few years include the Coastal Mixing and Optics (CMO) program (e.g., Dickey and Williams, 2001); the Coastal Benthic Optical Properties (CoBOP) program (see Limnology and Oceanography, volume 48[2], 2003, Special Issue: Light in Shallow Waters), the Thin Layers program (see Oceanography, volume 11(1), 1998, Special Issue: Focus on Thin Layers); the Ecology and Oceanography of Harmful Algal Blooms (ECOHAB) program (e.g., Walsh et al., 2003), and the Hyperspectral Coastal Ocean Dynamics Experiments (HyCODE; Oceanography, this issue). These collective experiments have greatly increased our understanding of bio-optical responses and effects as related to coupled physical-biologicalchemical-geological phenomena, including episodic and sometimes extreme events such as hurricanes, major rainfalls (e.g., associated with El Niño), intrusions of offshore waters (eddies and fronts), small-vertical scale aggregations of organisms, internal solitary waves, and red tides. These complex processes, which are typically nonlinear and often involve biological behavioral aspects, remain ripe for study. Yet, they are extraordinarily challenging to study in terms of the requisite temporal and spatial scales of sampling and the availability of limited numbers of obser- vational variables. Of course, modelers face these same challenges and constraints.

By conducting interdisciplinary bio-optical-physical studies, we are learning that very small time-space scale phenomena to long-time, global-scale phenomena need to be understood, particularly since energy (and interdisciplinary property variance) cascades in both directions: from larger to radiometric instruments and analyses represent major breakthroughs, and are discussed in this issue. Spectral light scattering information, along with absorption, is critical to understanding the complete optical field and the types of particles present, although for bio-optics, it is historically vastly underdetermined. The operational definition of hyperspectral for our purposes is "measurements made continuously across the visible portion of the electromagnetic spectrum (400-700 nm) with spectral resolution of less than $10 \mathrm{~nm}$ " (see Chang et al., this issue). The ability to highly resolve wavelengths of light is expected to open new research pathways (e.g., articles in this issue concerning determination of ocean bathymetry and phytoplankton species, among other applications). Also, radiative transfer models capable of hyperspectral resolution are being used much more frequently by observationalists as well as modelers, thanks to the development of user-friendly and efficient codes (e.g., Mobley, 1994).

The Office of Naval Research (ONR)sponsored Hyperspectral Coastal Ocean Dynamics Experiment (HyCODE) was devoted to field studies involving the simultaneous use of hyperspectral instruments deployed in situ and from aircraft. The sites for the experiments were off the coast of New Jersey (the Long-term Ecosystem Observatory, LEO-15) and on the West Florida Shelf (earlier related work was done as part of the ONR CoBOP project off Lee Stocking Island in the Bahamas; see Limnology and Oceanography, 2003, volume 48[2], Special Issue: Light in Shallow Waters). One of the objectives of HyCODE was to provide requisite scientific information for future remote sensing using hyperspectral imagers mounted on Earth-orbiting satellites. While some remote-sensing techniques, such as passive sensing of sea surface temperature, use electromagnetic (infrared) signals from the skin surface of the ocean, remote sensing of ocean color is more complicated. In par- 
ticular, remote measurement of color from space or an aircraft involves sensing of the near-surface volume of the ocean; the signal measured by satellite or aircraft color sensors is actually a weighted average over the light attenuation depth (roughly an e-folding length scale), which is dependent on the water's optical properties. Unfortunately, this weighted average does not contain the detailed information concerning the vertical structure of optical properties, information that we would find most useful. HyCODE was conceived to exploit the new capabilities of hyperspectral ocean color sensors, some of which are described in this issue. In particular, HyCODE took advantage of the fact that different wavebands of light penetrate to different depths because, in principle, the absorption and scattering of light within each waveband is dependent upon the optically influential substances within the water. Thus, there is the potential for using hyperspectral data to determine the presence of and to constrain the depths of optical layer in the ocean (e.g., Zaneveld and Pegau, 1998).

HyCODE was also poised to capitalize on advances in coupled atmosphere-ocean models and improved understanding of optically important ecosystem members. Specifically, HyCODE investigators are developing fully three-dimensional models that incorporate physical-biological-optical components and interactions. Data collected during the intensive HyCODE field campaigns are being used for testing these models. The model results (e.g., water-leaving radiance) will be compared with both aircraft and in situ observations obtained during HyCODE and these models will be used for future hyperspectral ocean-color satellite missions. The modeling approach should be useful in extracting vertical structure information pertinent to optical properties in the coastal ocean. Of course, these modeling efforts are highly dependent upon hyperspectral optical and physical data sets including the unique HyCODE field results presented in this issue.

Because of the fast-moving nature of biooptical oceanography, the papers appearing in this issue can be considered as progress

\section{TINY BUBBLES: AN OVERLOOKED OPTICAL CONSTITUENT}

While it can be imagined that one of the earliest descriptions of the ocean's surface viewed by man when he put forth to the ocean on rudimentary vessels might be the intensity of whitecapping, the science of understanding the influence of bubbles on marine light fields is an active area of research. Breaking waves at the ocean's surface inject bubbles and turbulence into the water column. During periods of rough weather, the scales of wave breaking tend to increase with increasing sea states, resulting in mixing of the surface waters and the turbulent transport of bubbles to depth. The bubbles injected by breaking will span several orders of magnitude in size from perhaps less than microns in diameter to $\mathrm{O}(1) \mathrm{cm}$. To complicate matters, the size distribution of bubble populations will evolve in time due to a complex interplay between the bubble rise speed, gas dissolution, surface tension, and turbulence, which are size-dependent, physical influences. In addition to breaking waves, bubble formation and stabilization result from biological processes such as photosynthesis in the surface layer, microbial decomposition in the sediments, the passage of low-pressure fronts that can bring gas out of solu- tion, and cavitation due to ships and other moving objects. The ubiquitous dissolved organic matter present in all oceans adheres onto bubbles almost immediately on formation, which significantly alters their physical dynamics, their optical characteristics, and potentially their gas dissolution rates.

Bubbles predominantly influence the optical properties of the upper ocean by scattering light. Their index of refraction, which is less than seawater, renders them very efficient at scattering; this is particularly true for the proportion of the total scattering in the backwards direction (see Boss et al., this issue). Despite the fundamental importance of particulate scattering for radiative transfer in the upper ocean, their central role in fixing the amplitude of light scattered out of the ocean, and their impacts on laser propagation, it is perhaps surprising that we cannot explain much more than 5 to 10 percent of the particulate backscattering in the ocean based on known constituents. Furthermore, we have been aware of this backscattering conundrum for a long time, almost as long as we have known its significance. One candidate to account for the "missing backscattering" is bubbles perhaps very small, stabilized bubbles, in the upper ocean.
The temporal and spatial variability of the bubble field has required the development of unique measurement approaches that include the use of underwater sound and optical imaging combined with the more traditional tools that optical oceanographers rely upon. For example, field efforts during the HyCODE program demonstrated with acoustic and optical techniques that the average optical scattering due to bubbles could range from $10^{-3} \mathrm{~m}^{-1}$ at a depth of $4 \mathrm{~m}$ to $10^{1} \mathrm{~m}^{-1}$ near the ocean surface during winds of $9 \mathrm{~m} / \mathrm{s}$ off the coast of New Jersey; significant increases were observed in the bubble component of the backscattering coefficient with the onset of high winds. Without accounting for bubbles, potentially large errors result in a wide variety of optical remote-sensing efforts including the remote-sensing retrieval of in-water constituents such as chlorophyll and laser imaging of the seafloor. 『s

Eric Terrill (et@mpl.ucsd.edu) is Assistant Research Scientist, Marine Physical Laboratory, Scripps Institution of Oceanography. Marlon Lewis is Professor, Department of Oceanography, Dalhousie University, Halifax, Nova Scotia, Canada. 
reports with views toward the future. Contributing authors were encouraged to present exciting new scientific results along with forward-looking, bold, thought-provoking, and even controversial ideas. This collection of papers will likely affect the way we think about bio-optical oceanography in the future. Brief synopses of the coastal optical and bio-optical problems and applications addressed by the authors follow.

Chang et al. introduce one of the most exciting new developments in optics and bio-optics, hyperspectral methods. They review the motivations for and evolution of hyperspectral technologies and their use by to be valuable complements to their other more conventional measurements.

Bissett et al. consider the important issue of scales of sampling in the coastal ocean, particularly regarding ocean color and optical properties and foci of key processes of interest. While much discussion has been devoted to this topic, new opportunities are enabling resolution of features as small as centimeters from in situ instrumentation and as small as a few meters from aircraft and likely spacecraft in the near future. Bissett et al. address several important questions concerning optimal sampling schemes as several constraints (e.g., observational

\section{...bio-optical sensors will be vital components of expanded}

autonomous sampling platforms, data transmission and power

\section{cable systems, and well-organized national, regional, and global observation systems and observatories.}

laboratory to in situ and aircraft-deployable instruments. They consider examples and uses of hyperspectral observations in terms of characterizing and quantifying a multiplicity of optical properties and biologically relevant variables and other potential hyperspectral applications (e.g., water depth or bathymetry, inherent optical properties, distinguishing phytoplankton populations based on characteristic pigment absorption spectra, plus many others that remain to be explored).

Sch ofield et al. provide a quick review for the non-remote-sensing oceanographer of some of the main optically active constituents that are significant in coastal waters. While "decoding" the optical complexity of these waters is difficult due to overlapping spectral signatures and particle sizes, recent advances in instrumentation offer the opportunity to tackle this problem. It is anticipated that biologists and chemists working in highly dynamic coastal ecosystems will find hyperspectral observations repeat cycle of an orbiting satellite, choices of viewing areas of geostationary satellites, spatial domains of sampling, altitudes of aircraft) must be considered. They present interesting examples of data sets that have been used to statistically quantify scales of variability with an eye toward future optimal sampling strategies and instrument configurations.

Boss et al. discuss the reasons why we should measure the backscattering coefficient. Now that several commercial sensors are available, backscatter is becoming relatively easy to measure. In fact, it can be measured in situ from moorings and mobile platforms. The backscattering coefficient provides information not available from other bio-optical measurements. Boss et al. note that all bio-optical quantities co-vary in a general way with the mass of material in the water, but that their responses to changes in composition, size distribution, shape, and internal structure are different. Thus, to study these secondary sources of optical variability, more than a single bio-optical measurement needs to be made. Boss et al. note that ocean color, i.e., remote-sensing reflectance, is proportional to the backscattering coefficient and emphasize that no fundamental understanding of ocean color is possible without an understanding of the sources of variability in the spectral backscattering coefficient.

Coble et al. introduce the topic of colored dissolved organic matter (CDOM), its optical and chemical properties, its origins, cycles, and demise, its importance oceanographically (i.e., ecology, photochemistry, and biogeochemistry, including carbon cycling), its measurement, and its use as an optical tool (i.e., as a water-mass tracer) for coastal oceanography. They present interesting contrasting examples of CDOM remotesensing data sets indicating spatial variability in CDOM in the Adriatic Sea, the Mississippi River plume, the West Florida Shelf, and Monterey Bay. Also considered are relations between elevated CDOM levels and red tides off the west coast of Florida.

Mobley et al. review the topic of optical classification of coastal waters, specifically Case 1 and Case 2 waters. They revisit the original paper on the classification scheme introduced by Morel and Prieur (1977) and suggest that it has likely been misinterpreted, especially in that a strict binary classification was not intended. Mobley et al. indicate that although the bipartite optical classification scheme has been useful in the past, it is time to consider a new approach. They state, "We therefore suggest that it is time simply to drop the Case 1 - Case 2 classification and focus on modeling water bodies according to whatever constituents are in the water column and whatever the bottom may be."

We are often struck by interesting features depicted in two-dimensional ocean color satellite images, but explanations for the origins of these fascinating patterns are often lacking or simply glossed over. However, Weisberg et al. provide an intriguing 
case study (West Florida Shelf region) with new insights into some of the fully three-dimensional, and time-dependent, interdisciplinary processes that contribute to complex surface expressions of color and temperature patterns. Processes deemed to be important include surface and bottom boundary-layer dynamics and mixing, coastal upwelling, and large-scale advection; both local and remotely forced phenomena come into play. The results reported by Weisberg et al. reinforce the point that fully three-dimensional, timedependent observations of physical and bio-optical processes using multi-platform approaches are essential for interpretation of ocean-color data and for the development of effective predictive models of primary production.

Philpot et al. discuss the motivation for and the use of remotely sensed hyperspectral imagery for determining coastal ocean bathymetry and bottom type in coastal areas where the bottom is visible through the water. Applications include creation of spatial time-series information for navigation, habitat classification, and recreation. The challenges of extracting bottom information from water-leaving radiation fields in coastal oceans, which are often changing quite rapidly both in terms of the water column optical and other properties and bottom materials, are outlined. They describe inversion methods, analyses, and approaches that can utilize hyperspectral, high-spatial-resolution data sets for deriving both bathymetric and bottom-type characterization information. Use of color hyperspectral remote-sensing data and radiative transfer model runs and neural networks for bottom characterization are described. Also, examples characterizing different bottom types using hyperspectral data are discussed.

Operational oceanography is clearly coming of age as discussed by Glen n et al. They review the brief history and concepts of operational oceanography and its many uses. Examples of ongoing, long-term ocean- observational programs include LEO-15, which have been supported by the National Oceanic and Atmospheric Administration's Undersea Research Program (NURP), the National Oceanographic Partnership Program (NOPP), and HyCODE, among others, are given. These illustrate the value of incorporating bio-optical instrumentation, as deployed from various autonomous sampling platforms, into long-duration, high-resolution sampling programs. Glenn et al. indicate that future observational systems will need to incorporate many different sampling platforms and models that are sustained for decades (see Weisberg et al., this issue).

The oceanographic research community is poised for even greater advances in measuring, understanding and utilizing bio-optical parameters in the coastal ocean, especially with the development of new biooptical models and sensors. Importantly, bio-optical sensors will be vital components of expanded autonomous sampling platforms (e.g., Dickey, 2003; Perry and Rudnick, 2003), data transmission and power cable systems (e.g., Glenn and Dickey, 2003; Oceanography volume 16[4], 2003, Special Issue: Ocean Observations), and well-organized national, regional, and global observation systems and observatories (e.g., Glenn et al., 2000; Oceanography volume 13[1], 2000, Special Issue: Coastal Ocean Observing Systems; Dickey, 2003; Oceanography volume 16[4], 2003, Special Issue: Ocean Observations). It may not be too much of a stretch to suggest that the day is nearing when oceanic bio-optical information and forecasts will be considered just as important to the coastal-dwelling public as weather forecasts.

\section{ACKNOWLEDGEMENTS}

I would like to thank the Office of Naval Research (ONR) for its support of my bio-optical and physical research since the early 1980s. In particular, I would like to acknowledge Joan Cleveland who managed the most recent HyCODE study, along with Steve Ackleson, Eric Hartwig, Rick Spinrad, Tom Swean, Lou Goodman, Ron Tipper, and Jim Eckman, who all played important roles in promoting and supporting bio-optical oceanography at ONR from its infancy to the present. Generous support has also been provided for complementary work by NSF, NOPP, NOAA, and NASA. Also, I would like to thank my many collaborators, including the authors contributing to this issue. 四

\section{REFERENCES}

Ackleson, S., 2001: Ocean optics research at the start of the 21st century. Oceanography, 14(3), 5-8.

Chang, G., T. Dickey, S. Jiang, D. Manov, and F. Spada, 2003: Optical methods for interdisciplinary research in the coastal ocean. Recent Research Developments in Optics, $3,249-270$.

Dickey, T., 2001: The role of new technology in advancing ocean biogeochemical research. Oceanography, 14(4), 108-120.

Dickey, T., 2003: Emerging ocean observations for interdisciplinary data assimilation systems. J. Mar. Syst., 40-41 5-48.

Dickey, T., and G. Chang, 2001: Recent advances and future visions: Temporal variability of optical and bio-optical properties of the ocean. Oceanography, 14(3), 15-29.

Dickey, T., and A.J. Williams, 2001: Interdisciplinary ocean process studies on the New England shelf. J. Geophys. Res., 106, 9,427-9,434.

Glenn, S., and T. Dickey, eds., 2003: Scientific Cabled Observations for Time Series (SCOTS). National Science Foundation Report, published by Consortium for Oceanographic Research and Education, Washington, D.C., 80 pp.

Glenn, S.M., T.D. Dickey, B. Parker, and W. Boicourt, 2000: Long-term real-time coastal ocean observation networks. Oceanography, 13, 24-34.

Mobley, C.D., 1994: Light and Water: Radiative Transfer in Natural Waters. Academic Press, San Diego, 592 pp.

Morel, A., and L. Prieur, 1977, Analysis of variations in ocean color. Limnology and Oceanography, 22(4), 709-722.

Pernetta, J.C., and J.D. Milliman, eds., 1995: Land-Ocean Interactions in the Coastal Zone Implementation Plan. IGBP Report No. 33. International Geosphere-Biosphere Programme, Stockholm, Sweden, 215 pp.

Perry, M.J., and D.L. Rudnick, 2003: Observing the oceans with autonomous and Lagrangian platforms and sensors: the role of ALPS in sustained ocean observing systems. Oceanography, 16(4), 31-36.

Sathyendranath, S. ed., 2000: Remote Sensing of Ocean Colour in Coastal and Other Optically-Complex Waters, Report of the International Ocean-Colour Coordinating Group (IOCCG). International Ocean-Colour Coordinating Group (IOCCG) Project Office, Bedford Institute of Oceanography, P.O. Box 1006, Dartmouth, Nova Scotia, Canada, 140 pp.

Walsh, J.J., R.H. Weisberg, D.A. Dieterle, R. He, B.P. Darrow, J.K. Jolliff, K.M. Lester, G.A. Vargo, G.J. Kirkpatrick, K.A. Fanning, T.T. Sutton, A.E. Jochens, D.C. Biggs, B. Nasaban, C. Hu, and F.E. Muller-Karger, 2003: Phytoplankton response to intrusions of slope water on the West Florida Shelf: Models and observations. J. Geophys. Res., 108, C6, 21, doi:10.1029/2002JC001406.

Zaneveld, J.R.V., and W.S. Pegau, 1998: A model for the reflectance of thin layers, fronts and internal waves and inversions. Oceanography, 11, 44-47. 